\title{
Efeitos ambientais e genéticos sobre escores visuais e ganho de peso à desmama de animais formadores da raça Brangus
}

\author{
Sandra Aidar de Queiroz ${ }^{1}$, Gabriela Zoccolaro Costa ${ }^{2}$, João Ademir de Oliveira ${ }^{3}$, Luiz Alberto Fries ${ }^{\star}$ \\ ${ }^{1}$ Departamento de Zootecnia (FCAV - UNESP), Jaboticabal, SP. Bolsista do CNPq. \\ 2 Zootecnista autônoma - Ribeirão Preto, SP. \\ ${ }^{3}$ Departamento de Ciências Exatas (FCAV - UNESP), Jaboticabal, SP. \\ 4 GenSys Consultores Associados S/C Ltda. \\ * In memoriam.
}

RESUMO - Estudaram-se os efeitos da idade da vaca ao parto e da idade do animal à desmama, bem como os efeitos genéticos aditivo direto e materno e da heterozigose individual, sobre os escores visuais de conformação, precocidade e musculatura e ganho de peso do nascimento à desmama, de animais formadores da raça Brangus. Foram analisados 53.683, 45.136, 52.937 e 56.471 dados de conformação, precocidade e musculatura à desmama e ganho de peso do nascimento à desmama, respectivamente, de animais nascidos entre 1986 e 2002, provenientes do arquivo zootécnico da empresa Gensys Consultores Associados S/C Ltda. Os efeitos de ambiente e genéticos sobre as características em estudo foram analisados pelo método de quadrados mínimos usando modelos matemáticos que incluíram grupo de contemporâneos como variável classificatória e a idade da vaca ao parto, a idade do animal à desmama e os efeitos aditivo direto e materno e da heterozigose individual como co-variáveis. Todos os efeitos incluídos nos modelos afetaram significativamente as características avaliadas, com exceção do efeito da idade da vaca ao parto sobre o ganho de peso do nascimento à desmama e do efeito aditivo materno sobre todas as características estudadas. Os efeitos ambientais e genéticos revelaram-se importantes fontes de variação para as características estudadas e devem, pois, ser considerados na distinção e comparação dos animais para seleção.

Palavras-chave: características de crescimento, conformação, efeitos de ambiente, heterozigose individual, musculatura, precocidade

\section{Environmental and genetic effects on visual scores and average daily weight gain at the weaning of animals used to form the Brangus breed}

\begin{abstract}
The objective of this work was to study the effects of age of cow at calving (IPV) and age of calf at weaning (IDD) as well as the direct additive genetic effects (AD) and maternal (AM), and the individual heterozygosity (HI) on visual scores of conformation (CD), precocity (PD) and musculature (MD) and average daily weight gain from birth to weaning (GND), for animals used to form the Brangus breed. The study analyzed 53,683, 45,136, 52,937 and 56,471 records on CD, PD, MD and GND, respectively for animals born from 1986 to 2002. The data were provided by "Gensys Consultores Associados S/C Ltda". The environmental and genetics effects on these traits were analyzed using the least square method applying mathematical models that included fixed effects of contemporary group (GC) and IPV, IDD, AD, AM and HI as covariates. All environmental effects included in the model showed significant influence on the evaluated traits at weaning, except for IDD on GND and AM on all traits. All traits were significantly influenced by AD and HI. These results indicated that environmental and genetic effects were important sources of variation for these traits and, consequently, they should be considered in genetic evaluations.
\end{abstract}

Key Words: conformation, environmental effects, growth traits, individual heterozygosity, musculature, precocity

\section{Introdução}

Com a competitividade na pecuária de corte brasileira, é necessário produzir carne de qualidade em sistemas de produção rentáveis, o que requer, entre outros, o uso de animais adequados às condições do ambiente de produção.
Uma alternativa para aumentar a produtividade consiste em aliar o potencial genético das raças européias especializadas na produção de carne à rusticidade e adaptabilidade das raças zebuínas.

A maior velocidade de crescimento e a boa adaptação dos produtos de cruzamentos entre Bos taurus e Bos

Este artigo foi recebido em 9/2/2007 e aprovado em 29/7/2008. 
indicus são proporcionadas pela combinação dos efeitos aditivos das raças utilizadas e pela heterose resultante dos genes em heterozigose (Muniz \& Queiroz, 1998). Assim, para incrementar a eficiência da seleção em populações de animais cruzados, as características avaliadas também devem ser adequadamente ajustadas para os efeitos de heterose (Roso \& Fries, 2000).

A expressão das características fenotípicas do indivíduo é resultado da ação de seus genes, dos efeitos ambientais e suas interações e o conhecimento e a estimativa de fatores de ajuste para esses efeitos (genéticos e de ambiente) são fundamentais para aumentar a precisão da seleção em progra mas de melhoramento animal.

$\mathrm{O}$ peso à desmama e o ganho de peso pré-desmama indicam o potencial de crescimento do bezerro e da habilidade materna da vaca (Borba, 1999). Segundo Fries (1984), a fase de vida entre o nascimento e a desmama é aquela em que os animais podem realizar ganhos de peso mais econômicos.

Como complementação às medidas de crescimento, vários programas de melhoramento genético têm adotado medidas de avaliação visual por escores. Por meio dos escores de conformação, avalia-se o potencial de produção de carcaças adequada à produção de carne. Na avaliação de precocidade, tenta-se predizer a capacidade do animal de atingir grau de acabamento mínimo de carcaça com peso vivo não elevado. Para musculatura, avalia-se o desenvolvimento muscular do animal como um todo.

Alguns autores (Cardoso et al., 2001; Jorge Junior et al., 2001; Dibiasi, 2003) destacaram a importância dos efeitos da idade da vaca ao parto e da idade do bezerro à desmama sobre os escores visuais. Este trabalho foi realizado utilizando-se dados de animais formadores da raça Brangus com o objetivo de identificar efeitos ambientais e genéticos que afetam os escores visuais de conformação, precocidade e musculatura à desmama e o ganho de peso pré-desmama.

\section{Material e Métodos}

Os dados de conformação, precocidade e musculatura à desmama e ganho de peso do nascimento à desmama utilizados neste estudo foram provenientes do arquivo zootécnico da empresa Gensys Consultores Associados S/C Ltda. e correspondem a observações de animais da raça Brangus nascidos no período de 1986 a 2002, em todos os meses do ano, de 110 rebanhos comerciais criados nas regiões Sul, Centro-Oeste e Sudeste.

As notas de conformação, precocidade e musculatura à desmama foram dadas a cada animal individualmente, segundo metodologia adotada pelo programa Natura para as raças Angus e Brangus, elaborado pela Gensys Consultores Associados S/C Ltda, que avalia os animais em relação ao grupo de contemporâneos. As notas foram atribuídas por um técnico treinado e variaram de 1 a 5 , de modo que 5 correspondeu à melhor expressão da característica.

A partir do arquivo original dos animais da raça Brangus, contendo 121.241 registros, foram eliminadas informações sobre animais com idade à desmama menor que 100 e maior que 300 dias, escores de conformação, precocidade e musculatura à desmama inferiores a 1 ou sem informação. Não foram considerados dados de animais com informações incompletas e valores que não eram biologicamente coerentes. Como conseqüência, o arquivo passou a contar com 53.683, 45.136, 52.937 e 56.471 observações para conformação, precocidade e musculatura à desmama e ganho de peso do nascimento à desmama, respectivamente.

Os valores para a heterozigose individual (HI) foram calculados, segundo Teixeira (2000), como: $\mathrm{HI}=$ raça do pai + raça da Mãe - 2 x (raça do pai × raça da mãe), em que raça $=$ fração zebuína do indivíduo.

A heterozigose materna não foi considerada neste estudo, pois foram utilizadas apenas vacas puras, como mães, tanto Nelore como Angus.

O ganho médio diário até a desmama foi calculado como a razão entre a diferença entre os pesos à desmama e ao nascer e o número de dias de idade do bezerro entre a data de desmama e a data de nascimento.

O grupo de contemporâneos foi composto por animais do mesmo sexo, mesma fazenda, mesma época e ano de nascimento e do mesmo dia, mês, fazenda e grupo de manejo de desmama. As variáveis dia, mês, fazenda e grupo de manejo de desmama foram consideradas em razão da ocorrência de desmama de animais do mesmo grupo de manejo em diferentes dias, bem como da transferência de bezerros de uma fazenda para outra logo após o nascimento. A idade da vaca ao parto variou de 2 a 15 anos e, embora o número de fêmeas Nelore tenha sido maior, a distribuição das fêmeas nas classes de idade foi proporcional nas duas raças. A época do nascimento foi classificada em quatro períodos de três meses, a partir de janeiro. Os efeitos aditivos direto $(\mathrm{AD})$ e materno (AM) foram definidos como a fração zebuína do produto e da mãe, respectivamente (Tabela 1).

Os efeitos de ambiente sobre os escores visuais e ganho de peso do nascimento à desmama foram analisados pelo método dos quadrados mínimos, utilizando-se o procedimento GLM do SAS (2000). O modelo geral proposto foi: $Y=X \beta+e$, em que: $\mathrm{Y}=$ vetor das variáveis dependentes (conformação, precocidade e musculatura à desmama e ganho de peso do nascimento à desmama); $\mathrm{X}=$ matriz de 
Tabela 1 - Constituição dos grupos genéticos e definição dos efeitos aditivos diretos e maternos

\begin{tabular}{|c|c|c|c|c|c|c|c|}
\hline \multicolumn{4}{|c|}{ Grupo genético ${ }^{1}$} & \multicolumn{4}{|c|}{ Efeito aditivo } \\
\hline \multirow[t]{2}{*}{ Touro } & \multirow[t]{2}{*}{ Vaca } & \multirow[t]{2}{*}{ Bezerro } & \multirow[t]{2}{*}{$\mathrm{N}^{\circ}$ bezerros } & \multicolumn{2}{|c|}{ Direto } & \multicolumn{2}{|c|}{ Materno } \\
\hline & & & & $\mathrm{N}$ & A & $\mathrm{N}$ & A \\
\hline $\mathrm{N}$ & $\mathrm{N}$ & $\mathrm{N}$ & 119 & 1 & 0 & 1 & 0 \\
\hline $\mathrm{A}$ & $\mathrm{N}$ & $1 \mathrm{~N} 1 \mathrm{~A}$ & 19.130 & $1 / 2$ & $1 / 2$ & 1 & 0 \\
\hline $\mathrm{N}$ & A & $1 \mathrm{~N} 1 \mathrm{~A}$ & 36 & $1 / 2$ & $1 / 2$ & 0 & 1 \\
\hline $1 \mathrm{~N} 1 \mathrm{~A}$ & $\mathrm{~N}$ & $3 \mathrm{~N} 1 \mathrm{~A}$ & 1.002 & $3 / 4$ & $1 / 4$ & 1 & 0 \\
\hline $3 \mathrm{~N} 1 \mathrm{~A}$ & $\mathrm{~A}$ & $3 \mathrm{~N} 5 \mathrm{~A}$ & 7.265 & $3 / 8$ & $5 / 8$ & 0 & 1 \\
\hline $1 \mathrm{~N} 3 \mathrm{~A}$ & $\mathrm{~N}$ & $5 \mathrm{~N} 3 \mathrm{~A}$ & 26 & $5 / 8$ & $3 / 8$ & 1 & 0 \\
\hline $3 \mathrm{~N} 1 \mathrm{~A}$ & $\mathrm{~N}$ & $7 \mathrm{~N} 1 \mathrm{~A}$ & 41 & $7 / 8$ & $1 / 8$ & 1 & 0 \\
\hline $3 \mathrm{~N} 5 \mathrm{~A}$ & A & $3 \mathrm{~N} 13 \mathrm{~A}$ & 514 & $3 / 16$ & $13 / 16$ & 0 & 1 \\
\hline $5 \mathrm{~N} 3 \mathrm{~A}$ & $\mathrm{~A}$ & $5 \mathrm{~N} 11 \mathrm{~A}$ & 1234 & $5 / 16$ & $11 / 16$ & 0 & 1 \\
\hline $3 \mathrm{~N} 5 \mathrm{~A}$ & $\mathrm{~N}$ & $11 \mathrm{~N} 5 \mathrm{~A}$ & 13.056 & $11 / 16$ & $5 / 16$ & 1 & 0 \\
\hline $5 \mathrm{~N} 3 \mathrm{~A}$ & $\mathrm{~N}$ & $13 \mathrm{~N} 3 \mathrm{~A}$ & 906 & $13 / 16$ & $3 / 16$ & 1 & 0 \\
\hline $11 \mathrm{~N} 5 \mathrm{~A}$ & A & $11 \mathrm{~N} 32 \mathrm{~A}$ & 315 & $11 / 32$ & $21 / 32$ & 0 & 1 \\
\hline $11 \mathrm{~N} 5 \mathrm{~A}$ & $\mathrm{~N}$ & $27 \mathrm{~N} 5 \mathrm{~A}$ & 123 & $27 / 32$ & $5 / 32$ & 1 & 0 \\
\hline A & $\mathrm{A}$ & A & 12.724 & 0 & 1 & 0 & 1 \\
\hline
\end{tabular}

${ }^{1}$ Os valores nos grupos genéticos representam a porção de cada raça na constituição dos grupos genéticos (por exemplo, 1N3A = 1/4 Nelore + 3/4 Angus); $\mathrm{N}^{\circ}=$ número de bezerros; $\mathrm{N}=$ Nelore; $\mathrm{A}=$ Angus.

incidência de efeitos fixos para as variáveis dependentes; $\beta=$ vetor dos efeitos fixos; e = vetor de efeitos residuais aleatórios.

Os efeitos fixos considerados foram grupo de contemporâneos, como variável classificatória, e como co-variáveis, efeitos lineares e quadráticos da idade da vaca ao parto(IPV) e da idade do animal à desmama (IDD), os efeitos lineares aditivo direto, aditivo materno e da heterozigose individual.

Posteriormente, os valores de conformação, precocidade e musculatura à desmama e ganho de peso do nascimento à desmama, em razão dos efeitos de ambiente, foram analisados por meio da seguinte equação de regressão: $\hat{y}=b_{0}+b_{1} x+b_{2} x^{2}$, em que: $b_{0}=$ intercepto; $b_{1}$ e $b_{2}=$ coeficientes de regressão linear e quadrático, respectivamente, e $\mathrm{x}=$ efeito observado (IPV e IDD).

O intercepto foi estimado como: $b_{0}=\mu-b_{1} \bar{x}-b_{2} \bar{x}^{2}$, em que: $\mu=$ média geral estimada pelo modelo; $b_{1}$ e $b_{2}=$ coeficientes de regressão linear e quadrática, respectivamente; $\bar{x}=$ média ponderada do efeito do ambiente estimado (IPV,IDD); e $\bar{x}^{2}=$ média ponderada do quadrado do efeito estimado.

As expressões de conformação, precocidade e musculatura à desmama e ganho de peso do nascimento à desmama, em decorrência dos efeitos genéticos (AD, AM e HI), foram analisadas considerando apenas a relação linear entre os efeitos.

\section{Resultados e Discussão}

Os valores obtidos para os escores de conformação, precocidade e musculatura à desmama e para ganho de peso do nascimento à desmama eram esperados (Tabela 2), uma vez que esses escores são atribuídos aos animais em relação ao lote em que se encontram e um animal considerado médio recebe escore 3.

$\mathrm{O}$ efeito de grupos de contemporâneos e os efeitos lineares e quadráticos das idades da vaca ao parto e do bezerro à desmama afetaram significativamente $(\mathrm{P}<0,01)$ as características avaliadas (Tabela 3 ), com exceção do efeito da idade do bezerro à desmama, que não foi significativo para a característica ganho de peso do nascimento à desmama $(\mathrm{P}>0,05)$.

As características conformação, precocidade e musculatura à desmama e ganho de peso do nascimento à desmama foram influenciadas significativamente $(\mathrm{P}<0,01)$ pelos efeitos lineares aditivo direto e da heterozigose individual, o que não ocorreu para o efeito linear aditivo materno (Tabela 3).

A pouca importância do efeito genético materno para estes animais deveu-se, possivelmente, à utilização de vacas puras (Nelore e Angus) como mães e à distribuição dos rebanhos nas Regiões Sul, Sudeste e Centro-Oeste do Brasil. Assim, vacas Angus foram melhores mães na Região Sul, enquanto as Nelore foram melhores nas Regiões Sudeste e Centro-Oeste. Desta forma, as diferenças entre as fêmeas tenderam a ser anuladas e este efeito não foi estatisticamente significativo para as características prédesmama. Carvalheiro et al. (2006), estudando o ganho médio diário pré-desmama em pesquisa com dados de várias composições genéticas entre Nelore e Hereford, relataram que os efeitos heteróticos favoreceram as composições genéticas intermediárias nas regiões temperadas e 
Tabela 2 - Estatísticas descritivas para as características conformação, precocidade, musculatura à desmama e ganho de peso do nascimento à desmama de bovinos formadores da raça Brangus

\begin{tabular}{|c|c|c|c|c|c|c|c|}
\hline Característica & $\mathrm{N}$ & Média & Moda & Mediana & Desvio-padrão & Amplitude & $\mathrm{CV}$ \\
\hline Conformação à desmama & 53.683 & 3,42 & 3 & 3 & 0,946 & $1-5$ & 27,62 \\
\hline Precocidade à desmama & 45.136 & 3,33 & 3 & 3 & 0,938 & $1-5$ & 28,19 \\
\hline Musculatura à desmama & 52.937 & 3,36 & 3 & 3 & 0,967 & $1-5$ & 28,77 \\
\hline $\begin{array}{l}\text { Ganho de peso do } \\
\text { nascimento à desmama }(\mathrm{kg} / \mathrm{dia})\end{array}$ & 56.471 & 0,663 & 0,658 & 0,666 & 0,132 & $0,328-1,492$ & 19,94 \\
\hline
\end{tabular}

$\mathrm{N}=$ número de observações; $\mathrm{CV}=$ coeficiente de variação.

Tabela 3 - Análises de variância para conformação, precocidade e musculatura à desmama e ganho de peso do nascimento à desmama de bovinos formadores da raça Brangus

\begin{tabular}{lcccc}
\hline Fonte de variação & \multicolumn{4}{c}{ Quadrado médio (Graus de liberdade) } \\
\cline { 2 - 5 } & CD & PD & MD & GND \\
\hline GC & $7,94^{* *}$ & $6,19^{* *}$ & $7,91^{* *}$ & $0,21^{* *}$ \\
& $(1960)$ & $(1568)$ & $(1945)$ & $(2029)$ \\
IVP & $98,54^{* *}$ & $120,23^{* *}$ & $134,44^{* *}$ & $4,74^{* *}$ \\
IVP2 & $84,14^{* * *}$ & $92,14^{* *}$ & $106,79^{* *}$ & $3,95^{* *}$ \\
IDD & $41,97^{* *}$ & $74,10^{* *}$ & $64,26^{* *}$ & $0,04^{\mathrm{NS}}$ \\
IDD2 & $5,21^{* *}$ & $20,99^{* *}$ & $15,88^{* *}$ & $0,01^{\mathrm{NS}}$ \\
AD & $7,55^{* *}$ & $22,26^{* *}$ & $15,68^{* *}$ & $0,33^{* *}$ \\
AM & $0,01^{\mathrm{NS}}$ & $0,05^{\mathrm{NS}}$ & $0,40^{\mathrm{NS}}$ & $0,04^{\mathrm{NS}}$ \\
HI & $88,46^{* *}$ & $30,94^{* *}$ & $13,79^{* *}$ & $1,61^{* *}$ \\
Resíduo & 0,745 & 0,797 & 0,782 & 0,093 \\
$R^{2}(\%)$ & 40 & 30 & 36 & 52 \\
CV $(\%)$ & 21,76 & 23,94 & 23,27 & 14,03 \\
\hline
\end{tabular}

**P $<0,01 ; \mathrm{ns}=$ não-significativo; GC = grupo de contemporâneos; IVP e IVP2 = idade da vaca ao parto, efeitos linear e quadrático; IDD e IDD2 = idade do animal à desmama, efeitos linear e quadrático; $\mathrm{AD}$ e $\mathrm{AM}=$ efeitos aditivo direto e materno linear; $\mathrm{HI}=$ heterozigose individual linear; $\mathrm{R}^{2}=$ coeficiente de determinação; CV = coeficiente de variação.

subtropicais, enquanto, nos trópicos, genótipos altamente adaptados apresentaram melhores desempenhos em comparação aos cruzamentos de Zebu com raças não adaptadas.

O efeito significativo $(\mathrm{P}<0,01)$ do grupo de contemporâneos sobre todas as características estudadas era esperado, uma vez que os fatores ambientais que o definiram afetam o desempenho dos animais no período pré-desmama.

$\mathrm{O}$ efeito significativo da idade da vaca ao parto sobre as características analisadas (Tabela 3 ) estaria relacionado à produção de leite e às mudanças fisiológicas relacionadas à maturidade do animal. Segundo Alencar (1987), a produção de leite das vacas foi responsável por 26,2 e 20,3\% do ganho em peso do nascimento à desmama nas raças Canchim e Nelore, respectivamente.

Em geral, a variação de ganho de peso do nascimento à desmama foi similar às encontradas para os escores de conformação, precocidade e musculatura à desmama (Figuras 1 e 2). Vacas que pariram aos 8 e 9 anos de idade foram aquelas que desmamaram bezerros com os melhores escores visuais e ganho de peso do nascimento à desmama, o que provavelmente se deve à maior produção de leite das vacas aos 8 anos de idade.

Estes resultados corroboram os obtidos por Pons et al. (1989a), que, ao estudarem dados de desmama de gado
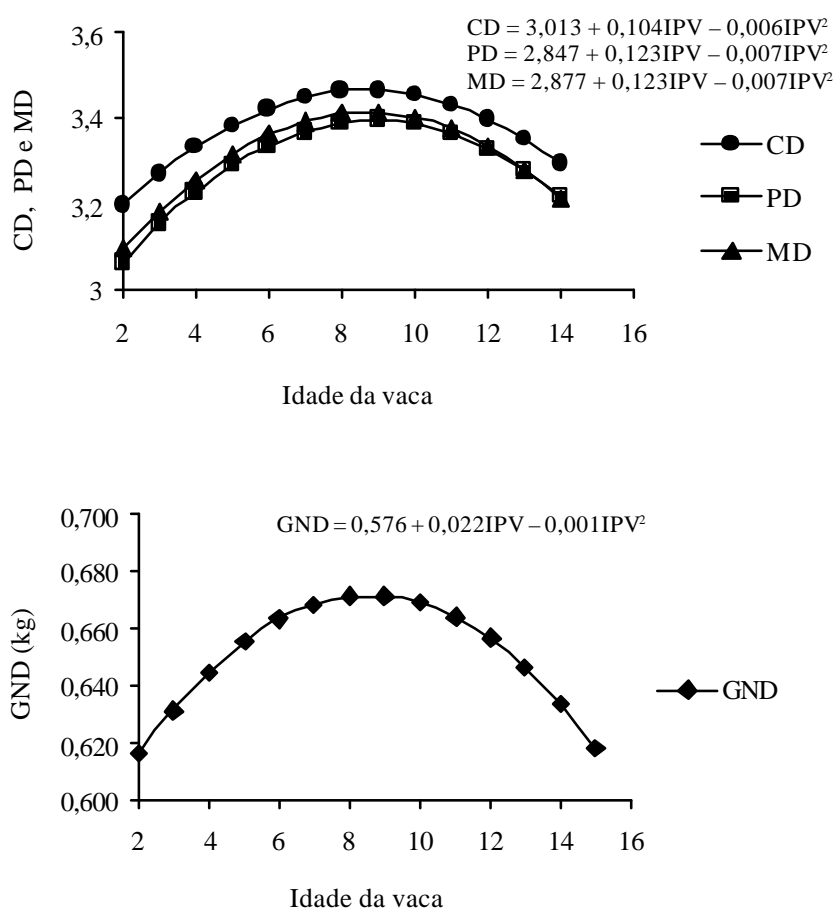

Figura 1 - Valores estimados para conformação (CD), precocidade (PD) e musculatura (MD), acima, e ganho de peso do nascimento à desmama (GND), abaixo, em relação à idade da vaca ao parto, em bovinos formadores da raça Brangus. 


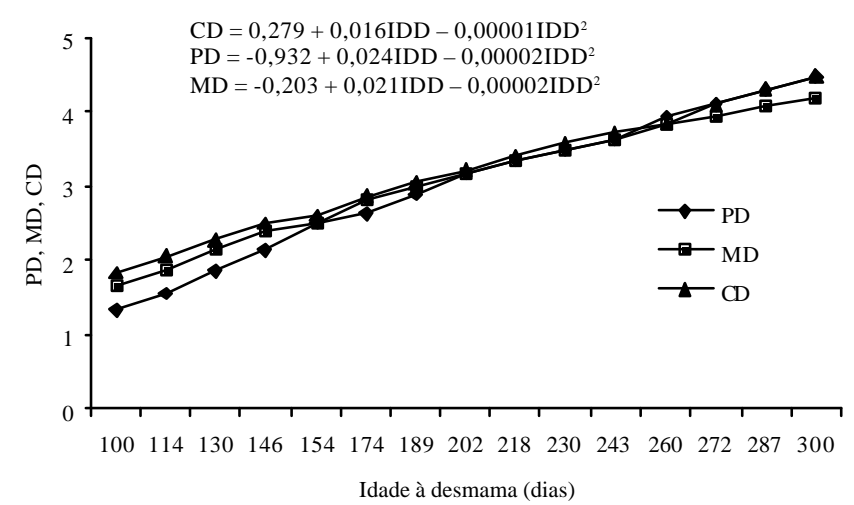

Figura 2 - Valores estimados para conformação(CD), precocidade (PD) e musculatura (MD), em função da idade do animal à desmama em bovinos formadores da raça Brangus.

Hereford no Rio Grande do Sul, constataram que a idade da vaca influenciou o escore de conformação do bezerro de forma curvilínea. Jorge Jr. (2002) também verificou, em animais da raça Nelore, que os escores visuais de conformação, precocidade e musculatura à desmamaaumentaram com a idade da vaca até 7 a 8 anos de idade e, em seguida, diminuíram. Dibiasi (2003), em animais da raça Nelore, também verificou aumento destes escores com o avançar da idade da vaca. Além disso, os maiores valores estavam associados a vacas que pariram aos 8-12 anos de idade. Resultados similares também foram relatados por Cardoso et al. (2001), Jorge Junior et al. (2001), Dal-Farra et al. (2002), Costa et al. (2004) e Rorato et al. (2004).

Teixeira (2000), avaliando a característica ganho de peso pré-desmama em animais mestiços, observou efeito quadrático significativo da idade da vaca, com pico de produção aos 7 anos. Essa tendência também foi verificada por outros autores (Paz, 1997; Bocchi et al., 1999; Sarmento et al., 2003).

Os efeitos significativos da idade (linear e quadrático) do animal à desmama sobre os escores de conformação, precocidade e musculatura à desmama observados neste estudo foram também relatados por Jorge Jr. (2002) naraça Nelore. Por outro lado, os resultados não-significativos desses efeitos para a característica ganho de peso do nascimento à desmama são contrários aos observados por Paz (1997) na raça Nelore e por Teixeira (2000), em animais cruzados Nelore $\times$ Hereford e Nelore $\times$ Angus, o queprovavelmente se deve ao fato deque o efeito da idade do animal já se encontra na equação do ganho de peso pré-desmama.

Os escores visuais aumentaram de forma curvilínea com a idade do animal à desmama (Figura 2). Animais mais jovens apresentaram menor desenvolvimento corporal à desmama, em comparação aos mais velhos, que receberam melhor classificação. Resultados semelhantes foram observados por Cardoso et al. (1999), Dal-Farra et al. (2002) e Costa et al. (2004). Cardoso et al. (2001), em pesquisa com bezerros Angus, relataram que a idade à desmama foi, entre os efeitos ambientais, a causa individual de maior variação nos escores visuais à desmama.

$\mathrm{O}$ efeito aditivo direto, que, neste estudo expressa a fração Nelore do produto, foi significativo $(\mathrm{P}<0,01)$ para todas as características estudadas (Tabela 3 ) e teve associação linear negativa com as características estudadas (Figura 3). Esse resultado indica que a maior proporção de genes da raça Nelore no bezerro em relação à de genes da raça Angus diminuiu as estimativas de ganho de peso do nascimento à desmama e de escores visuais à desmama, o que comprova a superioridade da raça Angus em ganhar peso em relação à Zebu, que é maisadaptada às condições brasileiras, porém mais tardia, enquanto a Angus é uma raça com precocidade de acabamento e qualidade de carcaça.

Trematore et al. (1998) também obtiveram efeito direto negativo da raça Nelore como desvio da raça Charolesa para ganho de peso do nascimento à desmama e ressaltaram que
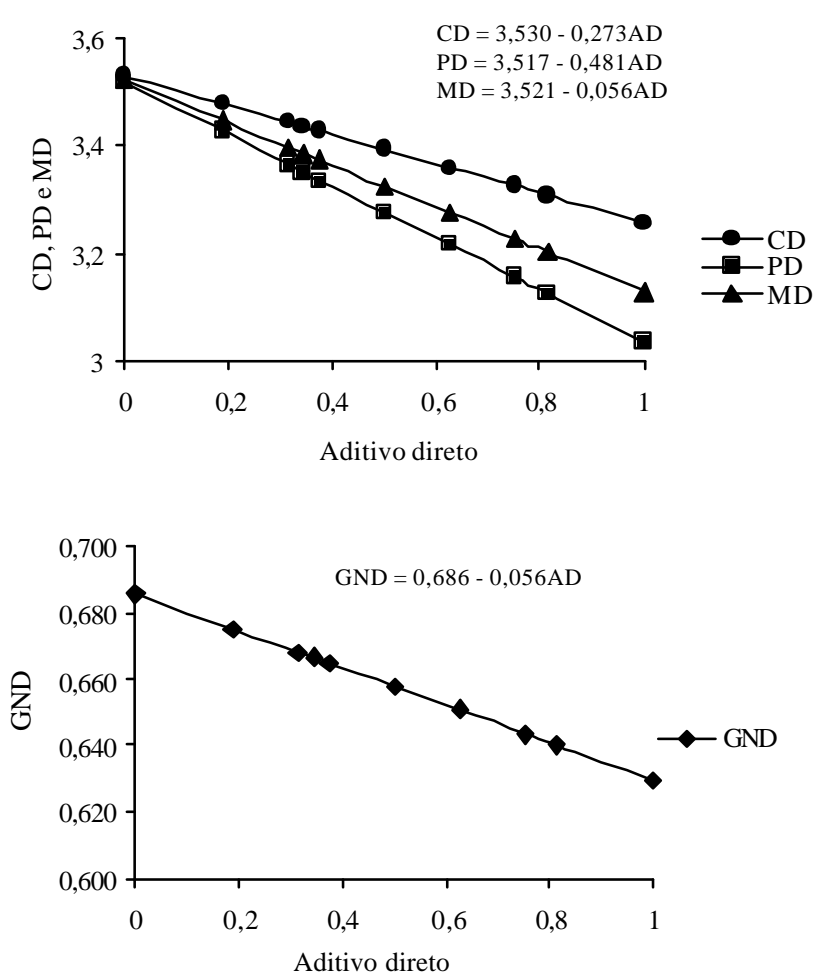

Figura 3 - Valores estimados para conformação (CD), precocidade (PD) e musculatura (MD), acima, e ganho de peso do nascimento à desmama (GND), abaixo, em relação ao efeito genético aditivo direto, em bovinos formadores da raça Brangus. 
a maior porcentagem de genes da raça Charolesa no bezerro proporcionou maior desenvolvimento do animal.

$\mathrm{O}$ efeito linear da heterozigose individual foi positivo e significativo $(\mathrm{P}<0,01)$ para todas as características estudadas (Tabela 3), o que indica que, quanto maior a heterozigose do bezerro, melhor seu desempenho: os animais $\mathrm{F} 1$, com heterozigose individual igual a 1, foram superiores (Figura 4). Como esperado, esses animais expressaram o grau máximo de heterose.

Resultados semelhantes foram encontrados por DalFarra et al. (2002) em avaliações visuais de conformação, precocidade e musculatura à desmama e ganho de peso do nascimento à desmama em animais cruzados, e Trematore et al. (1998) em avaliações de ganho de peso do nascimento à desmama em bovinos Charolês-Nelore.

Os resultados de cruzamentos em raças européias e indianas, como nos animais utilizados neste trabalho, comprovam melhor desempenho dos animais cruzados em relação aos puros, pela expressão da heterose, conforme relatado por Trematore et al. (1995), Euclides Filho et al. (1996) e Muniz \& Queiroz (1999).

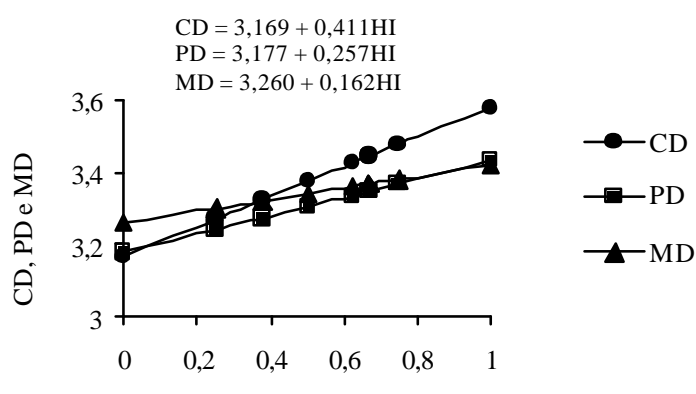

Heterozigose individual

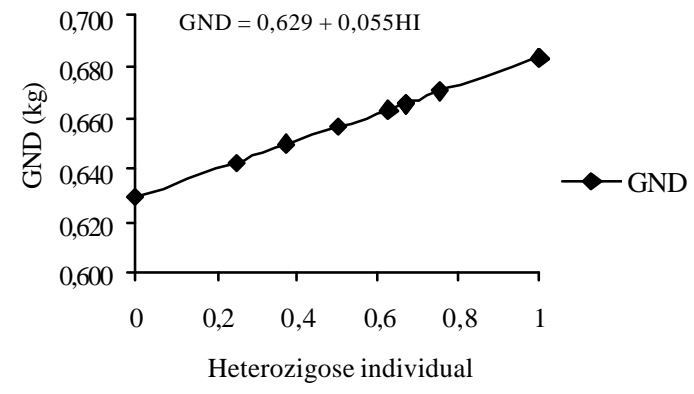

Figura 4 - Valores estimados para conformação (CD), precocidade (PD) e musculatura (MD), acima, e ganho médio de peso do nascimento à desmama (GND), abaixo, em relação à heterozigose individual $(\mathrm{HI})$, em bovinos formadores da raça Brangus.

\section{Conclusões}

O controle da idade da vaca ao parto e da idade do animal é fundamental em avaliações genéticas, pois essas características são importantes fontes de variação nos escores visuais de conformação, precocidade e musculatura e no ganho de peso à desmama. A fração zebuína do produto (efeito aditivo direto) e a heterozigose individual (efeito não aditivo) devem ser consideradas nos critérios de seleção de animais cruzados, pois também são importantes fontes de variação para as características estudadas.

\section{Literatura Citada}

ALENCAR, M.M. Efeitos da produção de leite sobre o desenvolvimento de bezerros Canchim. Revista Brasileira de Zootecnia, v.16, n.1, p.1-13, 1987.

BOCCHI, A.L.; FRIES, L.A.; ALBUQUERQUE, L.A. Efeito da idade da vaca e da data juliana de nascimento sobre o ganho médio diário de bezerros de corte durante o período pré desmama. In REUNIÃO ANAUL DA SOCIEDADE BRASILEIRA DE ZOOTECNIA, 36., 1999, Porto Alegre.Anais...Porto Alegre: Sociedade Brasileira de Zootecnia, 1999. p.154.

BORBA, L.H.F. Idade ao primeiro parto e características de crescimento de animais cruzados Blonde $D^{\prime}$ aquitaine $\times$ Zebu. 1999. 84f. Dissertação (Mestrado em Zootecnia) Faculdade de Ciências Agrárias e Veterinária, Universidade Estadual Paulista, Jaboticabal, 1999.

CAMPOS, L.T.; CARDOSO, F.F. Programa de melhoramento de bovinos de carne: manual do usuário. Pelotas: Associação Nacional de Criadores, 1995. 79p. ("Herd Book Collares").

CARDOSO, F.F. Caracterização genética do desempenho do nascimento à desmama de bovinos Aberdeen Angus criados no Rio Grande do Sul. 1999. 166f. Dissertação (Mestrado em Zootecnia) - Faculdade de Ciências Agrárias e Veterinárias, Universidade Federal de Pelotas, Pelotas, 1999.

CARDOSO, F.F.; CARDELLINO, R.A.; CAMPOS, L.T. Fatores Ambientais sobre escores de avaliação visual à desmama em bezerros ANGUS criados no Rio Grande do Sul. Revista Brasileira de Zootecnia, v.30, n.2, p.318-325, 2001.

CARVALHEIRO, R.E.C.G.; PIMENTEL, E.C.G.; CARDOSO, V. et al. Genetic effects on preweaning weight gain of Nelore-Hereford calves according to different models and estimation methods. Journal of Animal Science, v.84, p.2925-2933, 2006.

COSTA, G.Z.; QUEIROZ, S.A.; OLIVEIRA, J.A. et al. Influência de fatores ambientais sobre escores de conformação, precocidade e musculatura à desmama em animais cruzados F1 Zebu x Angus. I - Analise Estatística. In: SIMPÓSIO DA SOCIEDADE BRASILEIRA DE MELHORAMENTO ANIMAL, 5., 2004, Pirassununga. Anais... Pirassununga: Sociedade Brasileira de Melhoramento Animal, 2004. (CD-ROM).

DAL-FARRA, R.A.; ROSO, V.M.; SCHENKEL, F.S. Efeitos de ambiente e heterose sobre o ganho de peso do nascimento ao desmame e sobre os escores visuais ao desmame de bovinos de corte. Revista Brasileira de Zootecnia, v.31, n.3, p.1350-1361, 2002.

DIBIASI, N.F. Fatores de correção multiplicativos e aditivos para efeitos de ambiente sobre os escores de conformação, de precocidade e de musculatura à desmama em bovinos da raça Nelore. 2003. 48f. Monografia (Trabalho de Graduação em Zootecnia) - Faculdade de Ciências Agrárias e Veterinárias, Universidade Estadual Paulista, Jaboticabal, 2003.

EUCLIDES FILHO, K. Cruzamento em gado de corte. Campo Grande: EMBRAPA-CNPGC; Brasília: EMBRAPA-SPI, 1996. 68p. (EMBRAPA-SPI, Coleção Criar, 1). 
FRIES, L.A. A study of weaning weights in Hereford cattle in the state of Rio Grande do Sul, Brazil. 1984. 317p. Thesis (Ph.D. in Animal Breeding) - Iowa State University, Ames, 1984.

FRIES, L.A. Uso de escores visuais em programas de seleção para produtividade em gado de corte. In: SEMINÁRIO NACIONAL - REVISÃO DE CRITÉRIOS DE JULGAMENTO E SELEÇÃO EM GADO DE CORTE, 1996, Uberaba. Palestras... Uberaba: Associação Brasileira de Criadores de Zebu, 1996.

JORGE JR., J.; EL FARO, L.; ALBUQUERQUE, L.G. Estimativas de herdabilidade para os escores visuais de conformação, precocidade e musculatura, em um rebanho da raça Nelore. In: REUNIÃO ANUAL DA SOCIEDADE BRASILEIRA DE ZOOTECNIA, 38., 2001, Piracicaba. Anais... Piracicaba: Sociedade Brasileira de Zootecnia, 2001. p.618-619.

JORGE JR., J.; PITA, F.V.C., FRIES, L.A. et al. Influência de alguns fatores de ambiente sobre os escores de conformação, precocidade e musculatura à desmama em um rebanho da raça Nelore. Revista Brasileira de Zootecnia, v.30, n.6, p.16971703, 2001.

JORGE JR., J.Efeitos genéticos e de ambiente sobre os escores visuais de conformação, precocidade e musculatura no período pré-desmama em bovinos da raça Nelore. 2002. 70f. Dissertação (Mestrado em Zootecnia) - Faculdade de Ciências Agrárias e Veterinária, Universidade Estadual Paulista, Jaboticabal, 2002.

MUNIZ, C.A.S.D.; QUEIROZ, S.A. Avaliação do peso a desmama e do ganho médio de peso de bezerros cruzados, no Estado do Mato Grosso do Sul. Revista Brasileira de Zootecnia, v.27, n.3, p.504-512, 1998.

MUNIZ, C.A.S.D.; QUEIROZ, S.A. Avaliação de características de crescimento pós-desmama de animais Nelore e cruzados no Estado do Mato Grosso do Sul. Revista Brasileira de Zootecnia, v.28 n.4, p.713-720, 1999.

PAZ, C.C.P. Efeitos ambientais e genéticos que afetam o ganho de peso de pré desmama em bovinos da raça Nelore. 1997. 108f. Dissertação (Mestrado em Melhoramento Genético Animal) - Faculdade de Ciências Agrárias e Veterinárias, Universidade Estadual Paulista, Jaboticabal, 1997.

PONS, S.B.; MILAGRES, J.C.; TEIXEIRA, N.M. Efeitos de fatores genéticos e de ambiente sobre o crescimento e o escore de conformação em bovinos Hereford no Rio Grande do Sul.
I - Peso e escore de conformação à desmama. Revista Brasileira de Zootecnia, v.18 n.5, p.391-401, 1989.

ROSO, V.M.; FRIES, L.A. Avaliação das heteroses materna e individual sobre o ganho de peso do nascimento ao desmame em bovinos Angus x Nelore. Revista Brasileira de Zootecnia, v.29, n.3, p.732-737, 2000.

RORATO, P.R.N.; KIPPERT, C.J.; CAMPOS, L.T. et al. Fatores ambientais sobre escores de avaliação visual a desmama em bezerros da raça Charolês. In: SIMPÓSIO DA SOCIEDADE BRASILEIRA DE MELHORAMENTO ANIMAL, 5., 2004, Pirassununga. Anais... Pirassununga: Sociedade Brasileira de Melhoramento Animal, 2004. (CD-ROM).

STATISTICAL ANALYSIS SYSTEM - SAS. SAS/STAT User's guide. 8.2 ed. Cary: 2000. (CD-ROM).

SARMENTO, J.L.R.; PIMENTA FILHO, E.C.; RIBEIRO, M.N. et al. Efeitos ambientais e genéticos sobre o ganho em peso diário de bovinos Nelore no estado da Paraíba. Revista Brasileira de Zootecnia, v.32, n.2, p.325-330, 2003.

TEIXEIRA, R.A. Heterose materna e individual sobre o ganho de peso pré-desmama em bovinos Nelore $x$ Hereford $e$ Nelore x Angus. 2000. 75f. Dissertação (Mestrado em Zootecnia) - Faculdade de Ciências Agrárias e Veterinárias, Universidade Estadual Paulista, Jaboticabal, 2000.

TEIXEIRA, R.A. Efeitos genéticos aditivos e não-aditivos que influenciam características reprodutivas e de crescimento em bovinos de corte. 2004. 83f. Tese (Doutorado em Zootecnia) - Faculdade de Ciências Agrárias e Veterinárias, Universidade Estadual Paulista, Jaboticabal, 2004.

TEIXEIRA, R.A.; ALBURQUERQUE, L.G. Heteroses materna e individual para o ganho de peso pré-desmama em bovinos Nelore $x$ Hereford e Nelore x Angus. Arquivo Brasileiro de Medicina Veterinária e Zootecnia, v.57, n.4, p.518-523, 2005.

TREMATORE, R.L.; ALENCAR, M.M.; OLIVEIRA, J.A.L. Pesos de bovinos Nelore e cruzados Charolês - Nelore In: REUNIÃO ANUAL DA SOCIEDADE BRASILEIRA DE ZOOTECNIA, 32 ., 1995, Porto Alegre. Anais... Brasília: Sociedade Brasileira de Zootecnia, 1995. p.618-620.

TREMATORE, R.L.; ALENCAR, M.M.; BARBOSA, P.F. et. al. Estimativas de efeitos aditivos e heteróticos para características de crescimento pré-desmama em bovinos Charolês-Nelore. Revista Brasileira de Zootecnia, v.27, n.1, p.87-94, 1998. 